\title{
Registered nurses' views on telephone nursing for patients with respiratory tract infections in primary healthcare - a qualitative interview study
}

Elenor Kaminsky ${ }^{1}$, Ingrid Edvardsson Aurin ${ }^{2,3^{*}}$ (D), Katarina Hedin ${ }^{3,4}$, Lisbet Andersson ${ }^{5}$ and Malin André ${ }^{1}$

\begin{abstract}
Background: Telephone nursing in primary healthcare has been suggested as a solution to the increased demand for easy access to healthcare, increased number of patients with complex problems, and lack of general practitioners. Registered nurses' assessments may also be of great importance for antibiotic prescriptions according to guidelines. The aim of this study was to describe registered nurses' views of telephone nursing work with callers contacting primary healthcare centres regarding respiratory tract infections.
\end{abstract}

Methods: A descriptive, qualitative study was performed through interviews with twelve registered nurses in Swedish primary healthcare.

Results: The overarching themes for registered nurses' views on telephone nursing were captured in two themes: professional challenges and professional support. These included three and two categories respectively: Communicate for optimal patient information; Differentiate harmless from severe problems; Cope with caller expectations; Use working tools; and Use team collaboration. Optimal communication for sufficiently grasping caller symptoms and assess whether harmful or not, without visual input, was underlined. This generated fear of missing something serious. Professional support used in work, were for example guidelines and decision support tool. Colleagues and teamwork collaboration were requested, but not always offered, support for the interviewed registered nurses.

\footnotetext{
* Correspondence: ingrid.edvardsson@kronoberg.se

2Department of Research and Development, Region Kronoberg, Växjö,

Sweden

${ }^{3}$ Department of Clinical Sciences in Malmö, Family Medicine, Lund University, Malmö, Sweden

Full list of author information is available at the end of the article
}

(c) The Author(s). 2020 Open Access This article is licensed under a Creative Commons Attribution 4.0 International License, which permits use, sharing, adaptation, distribution and reproduction in any medium or format, as long as you give appropriate credit to the original author(s) and the source, provide a link to the Creative Commons licence, and indicate if changes were made. The images or other third party material in this article are included in the article's Creative Commons licence, unless indicated otherwise in a credit line to the material. If material is not included in the article's Creative Commons licence and your intended use is not permitted by statutory regulation or exceeds the permitted use, you will need to obtain permission directly from the copyright holder. To view a copy of this licence, visit http://creativecommons.org/licenses/by/4.0/ The Creative Commons Public Domain Dedication waiver (http://creativecommons.org/publicdomain/zero/1.0/) applies to the data made available in this article, unless otherwise stated in a credit line to the data. 


\begin{abstract}
(Continued from previous page)
Conclusions: The study deepens the understanding of telephone nursing as an important factor for decreasing respiratory tract infection consultations with general practitioners, thus contributing to decreased antibiotic usage in Sweden. To cope with the challenges of telephone nursing in primary healthcare centres, it seems important to systematically introduce the use of the available decision support tool, and set aside time for inter- and intraprofessional discussions and feedback. The collegial support and team collaboration asked for is likely to get synergy effects such as better work environment and job satisfaction for both registered nurses and general practitioners. Future studies are needed to explore telephone nursing in primary healthcare centres in a broader sense to better understand the function and the effects in the complexity of primary healthcare.
\end{abstract}

Keywords: Registered nurse, Telephone nursing, Telephone assessments, Respiratory tract infections, Primary healthcare, Qualitative study,

\section{Background}

Primary healthcare in the Western world faces vast challenges [1], with increasing demands for easy access. In addition, the number of patients with chronic and complex problems have increased, as have the difficulties in recruiting general practitioners (GPs). A suggested solution to these problems is the introduction of telephone nursing assessments by registered nurses (RNs) to reduce the numbers of face-to-face contacts and out-ofhours visits by GPs [2].

Sweden has a long tradition of telephone nursing in primary healthcare. When primary healthcare in the 1970s expanded, there was a scarcity of Swedish GPs. Thus, RN telephone nursing has become a central part of the primary healthcare system. This entails that RNs, based on caller symptoms, assess whether callers contacting primary healthcare centres (PHCCs) need to see a GP, be given self-care advice and stay home, or be recommended to visit other health services. The RN telephone work is commonly performed as part of the working day, in addition to seeing patients face-to-face. Most RNs working in Swedish primary healthcare have a specialist education, e.g. in district nursing, with their own PHCC surgery. Besides this, they often also have special assignments, e.g. child healthcare, diabetic, asthma or health-promoting appointments.

Today, patients are encouraged to call RNs at PHCCs as the first step for healthcare contacts. 'Drop in' appointments at PHCCs are also often available, where RNs make a first decision as to whether callers need a GP appointment or not. Swedish healthcare is publicly financed, and telephone calls to RNs are free of charge. GPs and RNs are salaried and typically work in group practices. In addition to PHCC telephone nursing during office hours, a national service, Swedish Healthcare Direct, offers telephone nursing around the clock [3].

Infections are common causes for primary healthcare contacts across Europe, accounting for around 30\% of all visits to a GP in Sweden, whereof respiratory tract infections (RTI) constitute around $60 \%$. In just under half of these GP visits, RTI patients are prescribed antibiotics [4]. Problems concerning RTI constitute a major portion of the calls for telephone assessments out-of-hours [5]. National guidelines for management of common infections have been in place in Sweden for 20 years, as well as a national web-based decision support tool (DST) available to aid RN assessments of callers' health problem urgency [6]. The DST was originally developed for telephone nursing at Swedish Healthcare Direct and is nationally updated on a regular basis in line with current guidelines.

Results from an earlier study suggest that RN's telephone assessments at PHCCs during office hours may be of great importance for the prescription of antibiotics according to guidelines [7]. Most RTIs are self-healing, where proper advice for self-care is the best option [8, 9]. At the same time, callers who would benefit from antibiotic treatment, and those with signs of a serious disease, must be identified for appropriate action. Thus, well-functioning RN telephone assessments of callers with RTI is important. Earlier studies suggest that DST, guidelines, local routines, continuous medical education (CME), as well as well-functioning cooperation with PHCC professionals and feedback, may facilitate correct RN assessments [7, 10].

Most research has examined the use of telephone nursing in an out-of-hours context [3, 11-13]. In recent years, some studies from UK report the effects of introducing telephone nursing in primary healthcare during office hours [14-17] but research concerning the RNs' experience of telephone work is sparse [18]. Therefore, the aim of this study is to describe RNs' views of telephone nursing work with callers contacting PHCCs regarding respiratory tract infections.

\section{Method}

\section{Study design}

This is a descriptive and inductive qualitative interview study. Data was collected through semi structured interviews with open-ended questions to stimulate the $\mathrm{RN}$ 
respondents own narratives [19]. The interviews were 30 to $40 \mathrm{~min}$ long, recorded and transcribed verbatim. An interview guide with open-ended questions was used. It contained questions regarding the telephone work, how caller needs and problems can be met and managed, if they used any available local guidelines and routines, how collaboration with GPs worked, and if CME was offered. Follow-up questions were asked to gain a deeper understanding.

\section{Study population}

A strategic sample of 12 RNs, working at eight PHCCs in southern and mid-Sweden, including daily work with telephone nursing, were interviewed for the study. Their working time with telephone nursing varied between and within PHCCs. The interviews were performed in January and February 2014, as part of a research project studying antibiotic prescription in PHCCs [6]. In that study, however, only six PHCCs were studied. The interview questions included: Can you please tell me about your telephone nursing work with callers contacting your PHCC about respiratory tract infections?; How are the assessments performed in these calls?; and What is difficult and which facilitators do you use in work? Further, were follow-up and probing questions asked, such as: Could you please tell me more about this; What do you mean by ...; and Could you please repeat and explain ... - to clarify and deepen the informants' answers.

The twelve RN interviews were randomly selected from every third interview out of the 26 previous project interviews, i.e. the first, fourth, seventh, tenth, thirteenth, sixteenth, ninteenth, twenty-second, twenty-fifth, resulting in nine interviews. In addition, to obtain a strategic sample representing $\mathrm{PHCCs}$ in regard to urban/rural areas, and prescription of antibiotic to a high/low extent, another three interviews were added to the first nine interviews. In all, the study data thus involved twelve interviews. See Table 1 for participating $\mathrm{RN}$ characteristics.

\section{Data analysis}

Qualitative content analysis with an inductive approach was carried out according to Graneheim and Lundman [19]. Hence, no pre-defined categories were used, but instead categories emerged from data. The analysis was performed in a number of steps. First, interview transcripts were read several times to catch the overall meaning. Meaningful units that corresponded to the study aim were then identified and selected from the text. Next, these meaningful units were condensed to a reduced description, i.e. the manifested content, as well as an interpretation of the underlying meaning, i.e. the latent content. The text units were then condensed and coded and finally put together into different categories. All authors analysed the text, independent of each other. The different steps of the analysis were discussed until consensus was reached. An example of the analysis process is shown in Table 2 .

\section{Ethics}

The study followed the ethical regulations and guidelines according to Swedish law [20] and conformed to the ethical principles defined in the World Medical Association Declaration of Helsinki [21]. The regional Ethical Review Board in Lund, Sweden (2013/679) approved the study. All interviewed RNs gave informed consent for participation. These were also informed that participation was voluntary and that they could withdraw from the study at any time, without giving a reason. The data have been handled confidentially, and the results are presented in a way that avoid identifying individuals.

\section{Results}

Two themes and five categories emerged from the data regarding describing $\mathrm{RNs}^{\prime}$ views of telephone nursing work with callers contacting PHCCs about respiratory tract infections. These are presented in Table 3. RN informant quotes are presented in italics and the interview numbers are presented in brackets.

\section{Professional challenges}

During the category analysis, the theme challenges emerged from the three categories: Communicate for optimal patient information, Differentiate harmless from severe problems, Cope with caller expectations. These all dealt with what RNs found difficult and challenging in their telephone nursing professional work at PHCCs. The three categories under this theme are further presented below.

Table 1 Description of characteristics of the interviewed RNs. $n=12$

\begin{tabular}{lc}
\hline Age of the interviewed RNs' median (range) & $48.5(32-65)$ \\
\hline Specialized district nursing (number) & 11 \\
Work experience, years in a PHCC median (range) & $14.5(4-25)$ \\
Working at a PHCC in urban areas (number) & 4 \\
Working at a PHCC with antibiotic prescription above average (number) & 5 \\
\hline
\end{tabular}


Table 2 Example of the analysis process

\begin{tabular}{|c|c|c|c|c|}
\hline Meaningful unit & Condensation & Code & Category & Theme \\
\hline $\begin{array}{l}\text { So my job in assessments is to distinguish what is like ... who } \\
\text { comes here and what should be self-care, and of what is com- } \\
\text { ing here, what could be something that is more serious? }\end{array}$ & $\begin{array}{l}\text { My job in assessments is to distinguish } \\
\text { what is self-care, and what could be } \\
\text { something more serious }\end{array}$ & $\begin{array}{l}\text { Assess } \\
\text { the level } \\
\text { of care }\end{array}$ & $\begin{array}{l}\text { Differentiate } \\
\text { harmless from } \\
\text { severity. }\end{array}$ & $\begin{array}{l}\text { Professional } \\
\text { challenges }\end{array}$ \\
\hline
\end{tabular}

\section{Communicate for optimal patient information}

Communication in calls was raised by the interviewed RNs as a difficult task. The lack of visual information and the need to rely solely on verbal caller information increased RNs' concern. They were worried about risks of misunderstanding the caller or that the caller would misinterpret given advice. They strived for optimal communication, and to obtain a clear patient picture during calls. For this, RNs asked callers a variety of questions, mainly about symptoms to come further in disease detection.

Many RNs tried to figure out if the caller was known to them and whether the symptom description was adequate. The importance of noticing implicit cues, such as background sounds, e.g. a supporting spouse, was underlined. Some callers were reported to describe their symptoms in detail and perhaps exaggerate, in order to get a GP appointment. Contrary to this, others provided brief information and underestimated serious symptoms:

Some say well, they are not very sick, and some are very sick, though they may not seem very sick, so it is ... I think it is basically difficult. Because you can get tricked by those who say, well, it's not so bad ... yes. But they are in fact very sick. (Interview 7)

Due to lack of observable signs, the RNs reported that they must rely on what they heard. For example, apart from caller descriptions of breathing problems, they also listened to callers' breathing and coughs. When RNs felt uncertain, they asked GPs at the PHCC for advice. In some PHCCs, RNs could offer face-to-face RN consultations, when the patient condition was unclear.

That's what we do, in dubious cases we can ... have the possibility to get them over here in some way

Table 3 Categories and themes for the described RNs' views of telephone nursing work with callers contacting PHCCs regarding respiratory tract infections

\begin{tabular}{lc}
\hline \multicolumn{1}{c}{ Categories } & \multicolumn{1}{c}{ Themes } \\
\hline Communicate for optimal patient information & Professional challenges \\
Differentiate harmless from severe problems & \\
Cope with caller expectations & \\
Use working tools & Professional support \\
Use team collaboration & \\
\hline
\end{tabular}

and make an assessment ... then you are able to see their skin colour and lots of other things. (Interview 4)

\section{Differentiate harmless from severe problems}

Another demanding assignment highlighted by the RNs, was to make correct assessments regarding symptom severity and whether the caller should see a physician (urgent or non-urgent) or receive $\mathrm{RN}$ self-care advice. The necessity to base assessments on thorough medical histories was emphasized. A need for sensitivity, nursing experience, and medical knowledge was also suggested in order to facilitate interpretation and assessments of the callers' condition over the telephone. The RNs were well aware of the risk of telephone nursing, regarding making the right decision, e.g. concerning if the person could manage with self-care advice, should get a GP appointment at once or could wait a few days. In this respect, the RNs described as functioning as a gatekeeper:

So my job in the assessment is to distinguish what is like ... who comes here and what should be self-care, and of what is coming here, what could be something that is more serious? (Interview 3)

The RNs sometimes made probabilistic assessments for diagnosis or considered other serious differential diagnoses. They feared missing serious diseases. Several described how they thought about possible underlying causes besides an infection when they for example were told about a cough. When self-care advice was given, the caller was prompted to call again if the symptoms did not disappear:

Well, all breathing problems and everything, and you would think ... yes, it is pulmonary embolism and ... these rapid ones, but it's a cough, there are usually some breathing problems then ... mm. Yes, I am very generous by saying they can get in touch in case of any small worsening. (Interview 6)

Regarding assessments, RNs expressed that telephone encounters with parents concerning sick children was the most difficult task in the telephone nursing work. They often felt uncertain about paediatrics and were therefore afraid of making mistakes. It was difficult to get a clear picture as to the degree of the child's illness, through the interview with the parent. Hence, GP 
appointments for children were given generously, despite a fully booked schedule. It was also reported to be important to comfort and calm parents:

I think that I am probably a bit uncertain there, when it comes to small children, so I may more often give them an appointment with the physician, as I feel that I cannot sort it out over the phone when it comes to children. (Interview 13)

Most of the RNs stated that they valued their work with self-care advice, since they found many respiratory tract infections to be self-healing and wanted to help callers avoid unnecessary antibiotics. The RNs also mentioned callers who were well aware of not using antibiotics unnecessarily, and who did not ask for medication. According to the interviewed RNs, the number of callers with this attitude had increased.

If you kind of explain what it is ... then I think people in general are very good about the fact that you should not take antibiotics unnecessarily, they don't really nag you. (Interview 3)

\section{Cope with caller expectations}

Another challenge according to the RNs, was the circumstance whereby some callers were perceived as impatient and required help and cures at once. Even before calling, they had decided to ask for a laboratory test, a GP appointment or antibiotics. Most of the persons experienced as demanding were reported to be young and employed, or on their way to holiday abroad. These people were not receptive to advice according to the RNs.

I don't think they are sick enough to be brought in ... Yes, I think ... if for example it's someone who does not seem very sick, but ... they still want to see a physician, because they want to get well quickly as they will be travelling abroad, etc. And it's like this ... they want penicillin, to get well right away, that's what they think. (Interview 1)

The RNs tried to handle the caller's expectations by discussing and explaining the reasons for symptoms and whether a GP appointment would be necessary or not. Simultaneously, the RNs underlined their ambition to satisfy the callers, comfort them and make them feel listened to. When unable to meet caller expectations through discussion, the RNs sometimes felt forced to book a GP appointment, even though this was against the guidelines.

Well, the important thing is to make them feel ... listened to and they are pleased and they don't hang up and are dissatisfied or worried or whatever, but you try to satisfy them, that's what I feel is important. (Interview 11)

The RNs underlined the importance of understanding and considering cultural aspects. Depending on callers' cultural backgrounds, some could have other expectations than the 'normal caller' regarding healthcare, e.g. other traditions regarding self-care advice or use of antibiotics. In these cases, the RN ambition to give self-care advice was often not well received.

It's a cultural issue, and therefore it's difficult to give self-care advice, as they don't want to understand that, no, and it's about seeing a physician, it's something within them. (Interview 5)

Parental wishes for a GP paediatric consultation only rarely included a wish for antibiotics according to the interviewed RNs. In these cases, some stated it was equally important to just comfort parents. These had found that many parents were comforted by receiving an RN appointment when their child was ill.

Yes, at least with parents and their children, I may feel, when they ... with the ears then, that they say that you don't need antibiotics treatment and it's nice not to have to give their children antibiotics, and the parents think so too, and it's very trying to do it, and of course you don't want to give the children medication they don't need. (Interview 1)

Sometimes you think that ... bring the children here, a bit because ... to calm the parents down. (Interview 6)

\section{Professional support}

Throughout the category analysis, the theme support also emerged from two categories In data. Use working tools and Use professional collaboration. Here, RNs talked about how to get professional support in their work via tools such as guidelines and the DST, and to collaborate with professional colleagues. However, not all informants reported to use these job supports. The two categories under the theme support will be further described below.

\section{Use working tools}

Concerning the RNs' reported use of work support, their use of and adherence to DST and guidelines seemed to vary. Some used the available DST. Others reported to know about it, but did not use it. Some RNs had not heard of the DST. Regarding guidelines, some read these when needed, while others remembered them by heart: 
I have them (the guidelines) memorised, I ask questions and then ... if I need to read up on it, I look it up and leaf through it. (Interview 3)

When guidelines were explicit, integrated into PHCCs' local routines, and thus well-known to all PHCC personnel, RNs reported that using them was easier. This made RNs aware of why and with what objectives a certain measure should be taken. When infectious symptom management routines were missing, some RNs reported that they instead tried to figure out what to do in order to fulfil the wishes of individual GPs.

The RNs' reported that opportunities for support via competence development in CME regarding infectious diseases varied. Some had participated in occasional educational activities, while others desired to be regularly informed. A common opinion was that GPs were offered more opportunities for CME, than RNs. Some RNs reported choosing not to prioritize education on infectious diseases, but rather participated in education in their field of special expertise and responsibility, such as diabetes or smoking cessation:

I have chosen other fields, yes. I guess it feels like the others have also prioritised other topics. Because it feels more ... that [infectious diseases] is more for the physicians ... but it's also very important to us, but ... the fact that we have chosen topics [education] that are for us to do, redressing a wound and ... yes, diabetes, smoking cessation, things like that ... but of course one would like to do that [infectious diseases] as well (Interview 10)

\section{Use team collaboration}

Another support in work reported by RNs, was to receive feedback in various ways from other professionals. This was particularly important for dealing with uncertainty regarding an assessment of caller symptoms, after a conversation over the phone and booking a GP consultation. Feedback was considered to be a source for learning for the future. This was managed in several ways by the interviewed RNs. Some read the medical records after GP consultations to find out how the physician had assessed the patient symptoms, as a second opinion to their own judgement. No RN expressed having received feedback from GPs in a systematic way. Instead, this had mostly happened on the RNs' own initiative, who could ask the GP in question for feedback.

Sometimes you can go back in the records, if you have a moment to spare, and see what the physician wrote in the medical records ... and what happened. I don't need to speak to the physician directly, as I can read it myself. That's what you can do. So that's a development. (Interview 5)

We try to tell the physicians that they are welcome to give us feedback about our GP bookings, so we can see if that was right or wrong. (Interview 5)

When the RNs felt uncertain and wanted advice from a GP about individual callers on the phone, or in their own clinic, they reported they had to 'disturb' the GPs in their work. Thus, this was a mutual problem for both RNs and GPs. The RNs stated that they had learned which GPs were OK to contact.

No, let's do it while they [patients] are still here [at the RN clinic] and go see the physician and discuss it, what will we do now, what do you think. Then, we always get a reply. (Interview 7)

Some PHCCs were reporzted to have regular meetings for RNs, with functioning collegial support, where management of individual caller or patient cases could be discussed. Others lacked support forums for joint discussions with colleagues, concerning assessments and management of diverse infectious disease symptoms.

Sometimes you feel, maybe, that you would need to meet, maybe just the RNs, and have a discussion, so we are bringing the same message over the phone, you know. A bit more than we are doing at the moment. (Interview 2)

RNs reporting this, often felt alone in making assessments over the phone. They wished for additional help from colleagues and increased information sharing and recommendations to be used in their work with callers. Hence, there were few opportunities for discussing issues when uncertain. Consequently, unpaid lunch breaks were sometimes used for collegial support, according to the interviewed RNs:

I guess generally ... that we are talking to each other, the RNs. Yes, we do. Yes ... [laughing] ... during our lunch ... Now, I have had this and that ... in the assessment, and imagine that ... this child had been sick for two days, like, and the mother is coming ... we can bring up different issues, what we will do. Yes, we communicate with each other, what did you do then? (Interview 2)

\section{Discussion}

This qualitative study on RNs' views of telephone nursing work with callers contacting PHCC regarding respiratory tract infections, resulted in two themes of 
professional challenges and professional support. The expressed challenges were Communicate for optimal patient information, Differentiate harmless from severe problems, and Cope with caller expectations. The communicated professional support were Use working tools; and Use team collaboration. The most striking finding was that besides highlighting challenges in the telephone nursing work, the interviewed RNs suggested how to get support in their work.

The RNs highlighted the importance of optimal communication in order to make correct assessments. They reported telephone nursing as challenging, regarding the assessment of both who the calling person is and the actual problem, due to relying only on what was heard. Furthermore, these two tasks were interrelated in an intricate way, in line with earlier studies [22]. Thus, training and communication skills seem as important as knowledge of the different guidelines for RTI [23]. The dual roles of telephone nursing have been described as care providers and gatekeepers [24]. Studies from UK primary healthcare of $\mathrm{RN}$ assessments during office hours reported a decrease in GP face-to-face contacts, but no decrease in overall clinical contacts [14-17].

In Sweden, telephone nursing has long been obligatory before receiving GP appointments. These are scarce, and consultation times are longer than in most European countries [25]. RNs must thus balance the risks of missing serious cases against taking responsibility for GP workloads [26]. The RNs consequently strived to frequently recommend self-care advice, to avoid unnecessary GP consultations and antibiotic prescriptions. This is in line with reports about telephone RNs' wish to educate callers and facilitate their learning [27]. The interviewed RNs lowered their threshold for allowing GP appointments concerning children. Second hand consultations, common in paediatric health calls [5], entailed further difficulties regarding assessments [28]. Comforting parents was described as important as curing, well in line with earlier studies [27, 29].

RN telephone nursing has been suggested as crucial for decreasing RTI consultations with GPs, and has thus contributed to the decrease of Swedish antibiotic prescriptions [7, 30]. The number of GP visits for RTI has almost halved for preschool children since late 90s [4, 31]. This change would not have been possible without RNs' promotion of basic guidelines, which is corroborated by all interviewed RNs confirming the view that many respiratory tract infections are self-healing. Moreover, these should be managed by self-care advice [32], in order to empower patients and reduce healthcare utilisation. This is possible in a healthcare system financed by taxes with well-educated and salaried RNs and GPs.

Surprisingly, the DST and guidelines were only partly known and used, in line with earlier research [22, 33]. In
Sweden the national RTI guidelines are implemented through outreach PHCC visits, both for GPs and RNs [30]. However, the guidelines were developed by physicians, focusing on diagnosis and treatment, and thus seldom elaborated on topic relevant for telephone nursing. The modest RN participation in creating the guidelines is astounding in a country with long traditions of PHCC telephone nursing. On the contrary, the national DST is designed for this purpose, and conforms to guidelines. The national DST is mandatory for RN work at Swedish Healthcare Direct but was not systematically introduced in primary healthcare at the time of the study. However, the national DST focuses on caller symptoms, while some RNs, in line with the guidelines, described thinking of diagnoses, e.g. concerning callers with cough. A more consistent use of DST might facilitate shared PHCC routines and teamwork between GPs and RNs, but should probably be complemented with local interprofessional discussions [7]. Strangely enough, no RN mentioned to use patient information on the national healthcare website, 1177 [34], or the Swedish Public Health Agency [35], available in several languages.

Contrary to the RN work at Swedish Healthcare Direct, the interviewed RNs had chosen to work at PHCCs for the possibility of face-to-face work with own patients [36]. The RNs reported that they preferred their main duties, and viewed answering telephone calls as imposed work, which is in line with Murdoch et al. 2015 [18]. Thus, CME for these common problems had low priority, both from an organizational and individual perspective. These circumstances could perhaps be overcome by education and facilitating PHCC adaption and transformation of guidelines among all staff through interprofessional discussions [7, 37]. A previous study [7] revealed that low-prescribing PHCCs regarding antibiotics had reserved time for regular meetings concerning medical issues, and prioritized training within and between professions. Somehow, RNs' knowledge and competence on telephone nursing issues in PHCCs, where RN selfadvice is crucial, is taken for granted by organisations. Thus, beyond continual forums for local CME, proper introductions and preparatory training for recently employed RNs is an urgent measure to establish which is also likely to decrease nursing turnover.

In line with Ahlstedt et al. [38], the interviewed RNs wished for feedback regarding their work. This could be facilitated at PHCCs by scheduling GP and colleague meetings for peer reviews, which no interviewed RN had experienced in a systematic way. Our earlier study as well as several studies emphasize well-functioning inter professional cooperation as the key for knowledge translation and evidence-based practice [7, 39, 40]. In many countries, RNs and GPs work together but the role and function of RN work vary between countries [41]. Close 
cooperation between RNs and GPs is likely to increase care quality and facilitate feedback [42]. A fruitful collaboration builds on mutual professional respect and trust, based on professional competence [41]. In this respect, the prerequisites are good in Sweden, where health professionals are well-educated. However, this study demonstrates that the RNs had to ask for feedback in order to receive this. The RNs not only wanted this from GPs, but also asked for support possibilities from colleagues and time for discussions within their own profession. These activities could decrease occupational stress and reduce feelings of loneliness in making telephone assessments [43]. At PHCCs with professional collaboration, i.e. open working climate, this had been organised by RN professionals themselves.

Telephone nursing in Swedish primary healthcare has been established for many years, however sparsely researched. The present study is one of a few international studies that explore telephone nursing within PHCCs. The described RNs' views may thus be valuable, not least for other countries implementing telephone nursing in primary healthcare settings. A strength of the study was that the research team contained both GPs and RNs. Qualitative content analysis was valuable for describing knowledge and understanding of the telephone nursing phenomenon [19]. The interviews were carried out as part of a project with the aim to explore factors important for antibiotics prescription [7]. Thus, the focus was not the wider perspective on RN performance or experiences of telephone nursing. No RN researcher was involved in the initial research group. If this had been the case, the interview guide may have been developed differently. Moreover, the interviewers' different pre-understandings of primary healthcare work, may be seen as both an advantage and disadvantage in the communication with informants. Data was collected in 2014, but the results are likely to still be highly relevant since RNs' telephone nursing work in Swedish primary healthcare has changed minimally over the past six years. The present study can henceforth serve as a valuable baseline measure to be compared with in future studies.

\section{Conclusion}

Two overarching themes were found, namely professional challenges and professional support to answer the aim of describing RNs' views of telephone nursing work with callers contacting PHCC regarding respiratory tract infection. The first theme contained three categories: Differentiate harmless from severe problems; Communicate for optimal patient information; Cope with caller expectations. The second theme included two categories: Use working tools and Use team collaboration. The present study is one of few international studies on telephone nursing at PHCCs. The results can be seen as a baseline to be compared with in future studies, regarding PHCC telephone nursing. The study deepens the understanding of telephone nursing as an important factor for decreasing RTI consultations with a GP, thus contributing to decreased antibiotic usage in Sweden. To cope with the challenges of telephone nursing in PHCCs, it seems important that managers in these organisations promote a systematic introduction for the use of DST and set aside time for inter- and intraprofessional discussions and feedback. The collegial support and team collaboration asked for is likely to get synergy effects such as better work environment and job satisfaction for both RNs and GPs. Future studies are needed to explore telephone nursing in PHCC in a broader sense to better understand the function and the effects in the complexity of primary healthcare.

\section{Abbreviations}

CME: Continuous medical education; DST: Decision support tool; GP: General practitioner; PHCC: Primary healthcare centres; RN: Registered nurse;

RTI: Respiratory tract infections

\section{Acknowledgements \\ Thank you for grants from the The Public Health Agency of Sweden. Special thanks to all interviewed RNs, who so willingly shared their views with the researchers, and to Lena Lennartsson for her excellent interview transcriptions.}

\section{Consent of publication}

Not applicable. The manuscript does not contain any individual personal data.

\section{Availability of data and material}

The study data have been handled in accordance with Swedish law. The interview dataset generated and analysed during the current study are not publicly available due to promises of participant anonymity and

confidentiality. However, on reasonable request the data could be available from the corresponding author.

\section{Authors' contributions}

The study was designed by MA and KH and they participated as interviewers. The initial deductive data analysis was done by LA and used as validation of the analysis carried out by IE, MA, KH and EK. The final data analysis of the interviews was discussed and consented to by all authors. A first draft of the article was developed by IE and MA. All authors then contributed to this, and finalized it together. EK was responsible for the final draft of the manuscript. All authors read and approved the final manuscript.

\section{Funding}

This study was funded by the Department of Research and Development, Region Kronoberg, which had no role in the design of the study or in writing the manuscript. Open access funding provided by Lund University.

\section{Ethics approval and consent to participate}

The study conforms to the principles outlined in the Declaration of Helsink and was approved by the Regional Ethical Review Board in Lund, Sweden (2013/679). Participation was voluntary. All participants gave their informed written consent to participate. All data were treated confidentially and could not be traced to any named person.

Competing interests

The authors declare that they have no competing interest. 


\section{Author details}

${ }^{1}$ Department of Public Health and Caring Sciences, Uppsala University, Uppsala, Sweden. ${ }^{2}$ Department of Research and Development, Region Kronoberg, Växjö, Sweden. ${ }^{3}$ Department of Clinical Sciences in Malmö, Family Medicine, Lund University, Malmö, Sweden. ${ }^{4}$ Futurum, Region Jönköping County, and Department of Health, Medicine and Caring Sciences, Linköping University, Linköping, Sweden. ${ }^{5}$ Department of Health and Caring Sciences, Faculty of Health and Life Sciences Linnaeus University, Linnaeus, Sweden.

\section{Received: 13 August 2019 Accepted: 7 July 2020} Published online: 14 July 2020

\section{References}

1. Bodenheimer T, Pham HH. Primary care: current problems and proposed solutions. Health Aff (Millwood) 2010;29(5):799-805. https://doi.org/10.1377/ hlthaff.2010.0026.

2. Chapman JL, Zechel A, Carter YH, Abbott S. Systematic review of recent innovations in service provision to improve access to primary care. $\mathrm{Br} J$ Gen Pract. 2004:54(502):374-81 https://bjgp.org/content/54/502/374

3. Kaminsky E, Roing M, Bjorkman A, Holmstrom IK. Telephone nursing in Sweden: a narrative literature review. Nurs Health Sci 2017;19(3):278-286. https://doi.org/10.1111/nhs.12349.

4. Tyrstrup M, Beckman A, Molstad S, Engstrom S, Lannering C, Melander E, et al. Reduction in antibiotic prescribing for respiratory tract infections in Swedish primary care- a retrospective study of electronic patient records. BMC Infect Dis 2016;16(1):709. https://doi.org/10.1186/s12879-016-2018-9.

5. Kaminsky E, Carlsson M, Hoglund AT, Holmstrom I. Paediatric health calls to Swedish telenurses: a descriptive study of content and outcome. J Telemed Telecare 2010;16(8):454-457. https://doi.org/10.1258/jtt.2010.100110.

6. Rådgivningsstödet webb https://www.1177.se/om-1177-vardguiden/om-11 77-vardguiden/radgivningsstodet-webb\%2D\%2Dett-stod-i-din-verksamhet/ [cited March 25 ${ }^{\text {th }}$ 2020].

7. Strandberg EL, Brorsson A, Andre M, Grondal H, Molstad S, Hedin K. Interacting factors associated with low antibiotic prescribing for respiratory tract infections in primary health care - a mixed methods study in Sweden. BMC Fam Pract 2016;17:78. https://doi.org/10.1186/s12875-016-0494-z.

8. Tan T, Little P, Stokes T, Guideline Development G. Antibiotic prescribing for self limiting respiratory tract infections in primary care: summary of NICE guidance. BMJ. 2008:337:a437. https://doi.org/10.1136/bmj.a437.

9. Cosby $J \mathrm{~L}$, Francis N, Butler CC. The role of evidence in the decline of antibiotic use for common respiratory infections in primary care. Lancet Infect Dis 2007;7(11):749-756. https://doi.org/10.1016/S1473-3099(07)702633.

10. Grimshaw JM, Eccles MP, Lavis JN, Hill SJ, Squires JE. Knowledge translation of research findings. Implementation science : IS 2012;7:50. https://doi.org/ 10.1186/1748-5908-7-50

11. Gamst-Jensen H, Frishknecht Christensen E, Lippert F, Folke F, Egerod I, Brabrand $M$, et al. Impact of caller's degree-of-worry on triage response in out-of-hours telephone consultations: a randomized controlled trial. Scand Trauma Resusc Emerg Med 2019;27(1):44. https://doi.org/10.1186/s13049019-0618-2.

12. Midtbo V, Raknes G, Hunskaar S. Telephone counselling by nurses in Norwegian primary care out-of-hours services: a cross-sectional study. BMC Fam Pract 2017;18(1):84. https://doi.org/10.1186/s12875-017-0651-z.

13. Cook EJ, Randhawa G, Large S, Guppy A, Chater AM, Pang D. Who uses NHS direct? Investigating the impact of ethnicity on the uptake of telephone based healthcare Int J Equity Health 2014;13:99. https://doi.org/10.1186/ s12939-014-0099-x

14. Campbell JL, Fletcher E, Britten N, Green C, Holt TA, Lattimer V, et al. Telephone triage for management of same-day consultation requests in general practice (the ESTEEM trial): a cluster-randomised controlled trial and cost-consequence analysis. Lancet. 2014;384(9957):1859-1868. https://doi. org/10.1016/S0140-6736(14)61058-8

15. Holt TA, Fletcher E, Warren F, Richards S, Salisbury C, Calitri R, et al. Telephone triage systems in UK general practice: analysis of consultation duration during the index day in a pragmatic randomised controlled trial. $\mathrm{Br}$ J Gen Pract 2016;66(644):e214-e218. https://doi.org/10.3399/bjgp16X684001.

16. Newbould J, Abel G, Ball S, Corbett J, Elliott M, Exley J, et al. Evaluation of telephone first approach to demand management in English general practice: observational study. BMJ. 2017;358:j4197. http://dx.doi.org/10.1136/ bmj.j4197.

17. Miller D, Loftus AM, O'Boyle PJ, McCloskey M, O'Kelly J, Mace D, et al. Impact of a telephone-first consultation system in general practice. Postgrad Med J 2019;95(1129):590-595. http://dx.doi.org/10.1136/postgradmedj-2019136557.

18. Murdoch J, Varley A, Fletcher E, Britten N, Price L, Calitri R, et al. Implementing telephone triage in general practice: a process evaluation of a cluster randomised controlled trial. BMC Fam Pract 2015;16:47. https://doi. org/10.1186/s12875-015-0263-4.

19. Graneheim UH, Lundman B. Qualitative content analysis in nursing research: concepts, procedures and measures to achieve trustworthiness. Nurse Educ Today 2004:24(2):105-112. https://doi.org/10.1016/j.nedt.2003.10.001.

20. The Act concerning the Ethical Review of Research Involving Humans http://www.codex.vr.se/en/manniska5.shtml (2003).

21. WMA Declaration of Helsinki - Ethical Principles for Medical Research Involving Human Subjects https://www.wma.net/policies-post/wmadeclaration-of-helsinki-ethical-principles-for-medical-research-involvinghuman-subjects/ [cited March 28 ${ }^{\text {th }} 2020$ ].

22. Purc-Stephenson RJ, Thrasher C. Nurses' experiences with telephone triage and advice: a meta-ethnography. J Adv Nurs 2010;66(3):482-494. https://doi. org/10.1111/j.1365-2648.2010.05275.x.

23. Greenberg ME. A comprehensive model of the process of telephone nursing. J Adv Nurs 2009;65(12):2621-2629. https://doi.org/10.1111/j.13652648.2009.05132.x

24. Holmstrom I, Dall'Alba G. 'Carer and gatekeeper' - conflicting demands in nurses' experiences of telephone advisory services. Scand J Caring Sci 2002; 16:142-148. https://doi.org/10.1046/j.1471-6712.2002.00075.x.

25. Irving G, Neves AL, Dambha-Miller H, Oishi A, Tagashira H, Verho A, et al. International variations in primary care physician consultation time: a systematic review of 67 countries. BMJ Open 2017;7(10):e017902. https://doi. org/10.1136/bmjopen-2017-017902

26. Fisher RF, Croxson CH, Ashdown HF, Hobbs FR. GP views on strategies to cope with increasing workload: a qualitative interview study. Br J Gen Pract 2017;67(655):e148-ee56. https://doi.org/10.3399/bjgp17X688861.

27. Kaminsky E, Rosenqvist U, Holmstrom I. Telenurses' understanding of work: detective or educator? J Adv Nurs 2009;65(2):382-390. https://doi.org/10. 1111/j.1365-2648.2008.04877.x.

28. Eriksson I, Ek K, Jansson S, Sjöström U, Larsson M. To feel emotional concern: a qualitative interview study to explore telephone nurses' experiences of difficult calls. Nursing Open 2019;6:842-848. https://doi.org/ 10.1002/nop2.264.

29. Halls A, Van't Hoff C, Little P, Verheij T, Leydon GM. Qualitative interview study of parents' perspectives, concerns and experiences of the management of lower respiratory tract infections in children in primary care. BMJ Open. 2017; 7(9):e015701 https://bmjopen.bmj.com/content/7/9/e015701.

30. Molstad S, Lofmark S, Carlin K, Erntell M, Aspevall O, Blad L, et al. Lessons learnt during 20 years of the Swedish strategic programme against antibiotic resistance. Bull World Health Organ 2017:95(11):764-773. https:// doi.org/10.2471/BLT.16.184374

31. Neumark T, Brudin L, Engstrom S, Molstad S. Trends in number of consultations and antibiotic prescriptions for respiratory tract infections between 1999 and 2005 in primary healthcare in Kalmar County, southern Sweden. Scand J Prim Health Care 2009;27(1):18-24. https://doi.org/10.1080/ 02813430802610784

32. Ingram J, Cabral C, Hay AD, Lucas PJ, Horwood J, Team T. Parents' information needs, self-efficacy and influences on consulting for childhood respiratory tract infections: a qualitative study. BMC Fam Pract 2013;14:106. https://doi.org/10.1186/1471-2296-14-106

33. Holmström I, Gustafsson S, Wesström J, Skoglund K. Telephone nurses' use of a decision support system: an observational study. Nursing \& Health Sciences 2019:21:501-507. https://doi.org/10.1111/nhs.12632.

34. Vårdguiden www.1177.se [cited March $25^{\text {th }}$ 2020].

35. Patientinformation - råd och fakta om antibiotikaanvändning https://www. folkhalsomyndigheten.se/smittskydd-beredskap/antibiotika-ochantibiotikaresistens/antibiotika-och-resistens/patientinformation: Folkhälsomyndigheten (The Public Health Agency of Sweden); [cited March $\left.25^{\text {th }} 2020\right]$.

36. Snooks HA, Williams AM, Griffiths L, Peconi J, Rance J, Snelgrove S, et al. Real nursing? The development of telenursing. J Adv Nurs 2008:61(6):631640. https://doi.org/10.1111/j.1365-2648.2007.04546.x. 
37. Gabbay J, Le May A. Practice-based evidence for healthcare. Oxon: Routledge; 2011.

38. Ahlstedt C, Eriksson Lindvall C, Holmström I, Muntlin Athlin Å. What makes registered nurses remain in work? An ethnographic study. Int J Nurs Stud 2019;89:612-624. https://doi.org/10.1016/j.jinurstu.2018.09.008.

39. Freund T, Everett C, Griffiths P, Hudon C, Naccarella L, Laurant M. Skill mix, roles and remuneration in the primary care workforce: who are the healthcare professionals in the primary care teams across the world? Int J Nurs Stud 2015;52(3):727-743. https://doi.org/10.1016/j.jinurstu.2014.11.014.

40. Pullon S. Competence, respect and trust: key features of successful interprofessional nurse-doctor relationships. J Interprof Care 2008;22(2):133147. https://doi.org/10.1080/13561820701795069.

41. Schadewaldt V, McInnes E, Hiller JE, Gardner A. Views and experiences of nurse practitioners and medical practitioners with collaborative practice in primary health care - an integrative review. BMC Fam Pract 2013;14:132. https://doi.org/10.1186/1471-2296-14-132.

42. MacLean L, Hassmiller S, Shaffer F, Rohrbaugh K, Collier T, Fairman J. Scale, causes, and implications of the primary care nursing shortage. Annu Rev Public Health 2014;35:443-457. https://doi.org/10.1146/annurev-publhealth032013-182508

43. Wahlberg AC, Bjorkman A. Expert in nursing care but sometimes disrespected-Telenurses' reflections on their work environment and nursing care. J Clin Nurs 2018;27:4203-4211. https://doi.org/10.1111/jocn.14622.

\section{Publisher's Note}

Springer Nature remains neutral with regard to jurisdictional claims in published maps and institutional affiliations.

Ready to submit your research? Choose BMC and benefit from:

- fast, convenient online submission

- thorough peer review by experienced researchers in your field

- rapid publication on acceptance

- support for research data, including large and complex data types

- gold Open Access which fosters wider collaboration and increased citations

- maximum visibility for your research: over $100 \mathrm{M}$ website views per year

At BMC, research is always in progress.

Learn more biomedcentral.com/submissions 